Original Research Paper

\title{
Factor Analysis on Onset of Ventilator-Associated Pneumonia for Inpatients in the Intensive Care Unit
}

\author{
${ }^{1}$ Takafumi Ooka, ${ }^{2}$ Yoshimasa Okamatsu, ${ }^{3}$ Yuriko Ando, ${ }^{4}$ Hiroshi Takano, \\ ${ }^{5}$ Youhei Tsuru, ${ }^{6}$ Motoko Ida, ${ }^{7}$ Shouji Hironaka, ${ }^{8}$ Yasafumi Maruoka and ${ }^{9}$ Yoshiharu Mukai \\ ${ }^{1,7}$ Department of Special Needs Dentistry, Showa University School of Dentistry, Japan \\ ${ }^{2}$ Dentistry, Showa University Hospital, Japan \\ 3,8 Department of Special Needs Dentistry, \\ Division of Community Based Comprehensive Dentistry, Showa Dental Hospital, Japan \\ ${ }^{4}$ Department of Nursing, Showa University Fujigaoka Hospital, Japan \\ ${ }^{5,6}$ Department of Nursing, Showa University Hospital, Japan \\ ${ }^{9}$ Emeritus, Showa University, Japan
}

\section{Article history}

Received: 24-10-2014

Revised: 24-11-2014

Accepted: 23-7-2015

Correspondence Author:

Takafumi Ooka

Department of Special Needs

Dentistry, Showa University

School of Dentistry, Japan

Email: takao3ka@dent.showa-u.ac.jp
Abstract: The objective of the present study is toassess risk factors" at the stage of proofs, including oral health status, with the development of VAP in perioperative patients, with the final aim of the establishing oral health management systems in acute care hospitals. Of the patients who were admitted to the Intensive Care Unit (ICU) of our university hospital from January to December 2011 and who underwent oral intubation, 11 patients who received a diagnosis of VAP (nine men and two women) and 11 control patients (eight men and three women) were selected as subjects for the present study. We first investigated the disease names listed in the medical records of subjects in the VAP group and then selected patients who had the same diseases as the control group subjects. Within one day after admission to the ICU, a dentist evaluated the oral health status of the patients and the lips, teeth, oral mucosa, gingiva, tongue and xerostomia were scored (0-12) based on the criteria of the Revised Oral Assessment Guide (ROAG). Furthermore, six items (operative duration, BMI, length of ICU stay, Acute Physiology and Chronic Health Evaluation (APACHE II) score and length of ventilator used) were extracted from patient medical records and investigated. The items were used as independent variables and their relationship with the development of VAP was examined by regression analysis. Oral health care was performed by a nurse four times per day, using a standard toothbrush or sponge brush. Moreover, this study was approved by the Ethics Committee of the Department of Dentistry in our university. When each factor was compared in the VAP group and the control group, the VAP group showed significantly higher scores for oral health status, length of ICU stay and length of ventilator used. Furthermore, when the development of VAP and the relationships with each factor were examined by regression analysis, a significant relationship with oral health status, operative duration, BMI and length of ventilator use was seen. The results of the present study suggest the possibility of various factors being involved in the development of VAP in orally intubated patients, such as the oral health status of the patient. Appropriate oral health care can aid the prevention of perioperative pulmonary infections.

Keywords: Ventilator, Pneumonia, Oral Intubation, Pulmonary Infections
(C) 2015 Takafumi Ooka, Yoshimasa Okamatsu, Yuriko Ando, Hiroshi Takano, Youhei Tsuru, Motoko Ida, Shouji Hironaka, Yasafumi Maruoka and Yoshiharu Mukai. This open access article is distributed under a Creative Commons Attribution (CCBY) 3.0 license. 


\section{Introduction}

In recent years, oral care has been shown to be effective in the prevention of pulmonary infections, including aspiration pneumonia (Segers et al., 2008; Of these cases, because contamination of the oral cavity or pharynx in patients receiving artificial respiration can lead to Ventilator-Associated Pneumonia (VAP), a serious form of pneumonia, the importance of oral care during the acute phase has become widely known (Feider et al., 2010; Hutchins et al., 2009; Mori et al., 2006). Because perioperative artificial respiration is a commonly performed procedure, prevention of VAP is a major issue for the general care of patients. VAP is due to the invasion of the trachea and lungs by normal oral and pharyngeal microbial flora via oral intubation tube. In addition, risk factors such as patient bed positioning, level of sedation and gastroesophageal reflux are thought to increase the risk of development of VAP, indicating that many factors are involved (Parker et al., 2008; Akça et al., 2000). For this reason, various bundles are used as prophylaxis and general care and management of oral hygiene are performed (Rello et al., 2010). However, because multiple factors are involved in the development of VAP, no gold standard for prophylactic treatment has been established.

The objective of the present study is to elucidate risk factors for the development of VAP in patients in our university hospital and to examine the relationship of VAP development in perioperative patients with oral health status and the preoperative and postoperative status of the patients.

\section{Materials and Methods}

Of patients who were admitted to our university hospital from April 2010 to March 2012 and received artificial respiration via oral intubation, 17 patients who received a diagnosis of VAP (VAP group) and 17 patients in whom pneumonia did not develop (control group) were selected as subjects for the present study. Both the VAP group and the control group comprised 11 men and six women. We investigated the diseases responsible for
ICU admission (principal disease) and age of patients. We selected control subjects who had the same diseases and were as near in age to the VAP subjects as possible. The disease names of the control subjects were extracted from the hospital medical records. Based on the criteria of preceding studies, we classified the principal diseases into four groups: Cerebrovascular diseases; pulmonary diseases; gastrointestinal diseases; and circulatory diseases (Ooka et al., 2013; 2012). Subject attributes and representative principal diseases are shown in Table 1. Patients with unclear principal diseases (multiple organ failure, metastasis of malignant neoplasms, etc.) were excluded from the present study.

Within $24 \mathrm{~h}$ of ICU admission, the oral health status of the subjects was assesed by a dentist and dental hygienist of the oral health care center in our hospital. Oral health was divided into eight categories and scored based on the criteria of the Revised Oral Assessment Guide (ROAG) (Andersson et al., 2002; Eilers et al., 1998). Evaluation items and criteria are shown in Table 2. Oral care was performed in the ICU four times daily $(6: 00,12: 00,18: 00$ and 24:00). Oral health status was assessed between 13:00 and 14:00 after the second oral treatment. We investigated systemic factors from medical records such as operative duration, Body Mass Index (BMI), albumin before operation, length of ICU stay, length of oral intubation, APACHE II score and length of ventilator use. Eight items, including the ROAG score for these items, were compared in the VAP group and control group. We examined these items as independent variables and performed a regression analysis on their relationship with VAP development. We also performed a regression analysis on the relationship of each evaluation item related to oral health status with VAP development. The VAP group and control group were compared using Man-Whitney's $U$ test and regression analysis was performed using logistic regression analysis.

Table 1. Attribution of each group

\begin{tabular}{lll}
\hline Items & VAP group & Control group \\
\hline Age & $65.7 \pm 12.3$ years old & $64.4 \pm 13.1$ years old \\
& $(37-81$ years old $)$ & $(33-80$ years old $)$ \\
Gender & Male, 13 & Male, 9 \\
& Female, 4 & Female, 8 \\
Primary disease & Cardiovascular disease, 11 & Cardiovascular disease, 11 \\
& Cerebrovascular disease, 4 & Cerebrovascular disease, 4 \\
Length of hospital stay & Gastrointestinal disease, 2 & Gastrointestinal disease, 2 \\
& $65.7 \pm 28.5$ days & $59.5 \pm 28.4$ days \\
Situation of operation & $(32-113$ days $)$ & $(26-107$ days $)$ \\
& Elective, 10 & Elective, 8 \\
& Emergency, 7 & Emergency, 9 \\
\hline
\end{tabular}


Takafumi Ooka et al. / Current Research in Dentistry 2015, 6 (1): 7.12 DOI: $10.3844 /$ crdsp.2015.7.12

\begin{tabular}{|c|c|c|c|}
\hline Category & Rating 0 & Rating 1 & Rating 2 \\
\hline Lips & Smooth and pink & Dry or cracked and/or angular chelitis & Ulcerated or bleeding \\
\hline Teeth/dentures & Clean, no debris & Plaque or debris in local areas & Plaque or debris generalized \\
\hline Mucous membrane & Pink and moist & $\begin{array}{l}\text { Dry and/or change in color, } \\
\text { red blue-redor white }\end{array}$ & $\begin{array}{l}\text { Very red, or thick, white coating } \\
\text { Blisters or ulceration }\end{array}$ \\
\hline Gums & Pink and firm & Edematous and/or red & Bleeding easily under finger pressure \\
\hline Tongue & $\begin{array}{l}\text { Pink, moist and } \\
\text { papillae present }\end{array}$ & $\begin{array}{l}\text { Dry, no papillae present or } \\
\text { change in color, red or white }\end{array}$ & $\begin{array}{l}\text { Very thick white tongue coating } \\
\text { Blisters or ulceration }\end{array}$ \\
\hline Saliva & $\begin{array}{l}\text { No friction between } \\
\text { the mouth mirror } \\
\text { and mucosa }\end{array}$ & $\begin{array}{l}\text { Slightly increased friction, no } \\
\text { tendency for the mirror to } \\
\text { adhere the mucosa }\end{array}$ & $\begin{array}{l}\text { Significantly increased friction, the } \\
\text { mirror adhering or tending to adhere } \\
\text { to the mucosa }\end{array}$ \\
\hline Condition of teeth & $\begin{array}{l}\text { There are not teeth } \\
\text { needing dental } \\
\text { treatment }\end{array}$ & $\begin{array}{l}\text { There are the teeth disturbing the oral } \\
\text { care or becoming the source } \\
\text { of infection }\end{array}$ & $\begin{array}{l}\text { There are teeth needing immediate } \\
\text { dental treatment including } \\
\text { tooth extraction }\end{array}$ \\
\hline Halitosis & No halitosis & $\begin{array}{l}\text { Halitosis is felt when closer to less } \\
\text { than } 30 \mathrm{~cm} \text { from oral cavity }\end{array}$ & $\begin{array}{l}\text { Halitosis is felt when separated from } \\
\text { oral cavity more than } 30 \mathrm{~cm}\end{array}$ \\
\hline
\end{tabular}

Table 3. Results of comparison between the groups

\begin{tabular}{|c|c|c|c|}
\hline Items & VAP group & Control group & $\mathrm{p}$ value \\
\hline Operative duration & $\begin{array}{l}7.8 \pm 3.4 \mathrm{~h} \\
(2-13 \mathrm{~h})\end{array}$ & $\begin{array}{l}5.3 \pm 2.3 \mathrm{~h} \\
(2.5-10 \mathrm{~h})\end{array}$ & n.s. \\
\hline BMI & $\begin{array}{l}21.6 \pm 3.4 \\
(15.5-27.1)\end{array}$ & $\begin{array}{l}22.9 \pm 4.1 \\
(18.7-30.5)\end{array}$ & n.s. \\
\hline Albumin before operation & $\begin{array}{l}3.8 \pm 0.7 \mathrm{~g} / \mathrm{dL} \\
(2.3-4.8)\end{array}$ & $\begin{array}{l}3.3 \pm 0.9 \mathrm{~g} / \mathrm{dL} \\
(2.1-4.6)\end{array}$ & $*$ \\
\hline Length of ICU stay & $\begin{array}{l}31.0 \pm 21.5 \text { days } \\
\text { (12-87 days) }\end{array}$ & $\begin{array}{l}15.8 \pm 17.0 \text { days } \\
(3-60 \text { days })\end{array}$ & $*$ \\
\hline Length of oral intubation & $\begin{array}{l}29.0 \pm 22.1 \text { days } \\
\text { (9-87 days) }\end{array}$ & $\begin{array}{l}13.5 \pm 16.8 \text { days } \\
\text { (2-60 day) }\end{array}$ & $* *$ \\
\hline APACHE II score & $\begin{array}{l}15.2 \pm 6.6 \\
(5-26)\end{array}$ & $\begin{array}{l}12.0 \pm 2.3 \\
(9-17)\end{array}$ & n.s. \\
\hline Length of ventilator use & $\begin{array}{l}29.1 \pm 22.2 \text { days } \\
(6-87 \text { days })\end{array}$ & $\begin{array}{l}12.4 \pm 17.0 \text { days } \\
(2-60 \text { days })\end{array}$ & $*$ \\
\hline ROAG score & $\begin{array}{l}4.7 \pm 1.9 \text { points } \\
(3-8 \text { points })\end{array}$ & $\begin{array}{l}2.5 \pm 1.7 \text { points } \\
(0-5 \text { points })\end{array}$ & $*$ \\
\hline
\end{tabular}

$*: \mathrm{p}<0.05, * *: \mathrm{p}<0.01$

n.s. : not significant

by Mann-Whitney’s U test

\section{Results}

The results of the comparison of operative duration, BMI, albumin at time of admission to ICU, length of ICU stay, length of oral intubation, APACHE II score, length of ventilator use and ROAG score between the VAP group and the control group is shown in Table 3.

No statistical difference was seen between the groups for operative duration, BMI, or APACHE II score. However, the VAP group showed a significantly higher score for albumin before operation, length of ICU stay, length of oral intubation, length of ventilator use and ROAG score (length of oral intubation was $p<0.01$, others were $\mathrm{p}<0.05)$.

The test results for the correlation between VAP development and the eight evaluation items areshown in Table 4. The VAP development showed a significant relationship with operative duration, length of ICU stay, length of ventilator use and ROAG score. Similarly, the test results for the correlations between VAP development and ROAG score with each item are shown in Table 5. Correlations between VAP development and saliva was seen $(p<0.05)$. No statistical relationship was seen with the other items.
Table 4. Correlation of VAP onset and each item

\begin{tabular}{lrll}
\hline Items & OR & $95 \%$ CI & $\mathrm{p}$ value \\
\hline Operative duration & 3.1 & $0.03-0.14$ & $*$ \\
BMI & -1.3 & $-0.09-0.02$ & n.s. \\
Albumin before operation & 1.2 & $0.02-0.05$ & n.s. \\
Length of ICU stay & -2.4 & $-0.06-0.03$ & $*$ \\
Length of oral intubation & 2.3 & $0.002-0.14$ & $*$ \\
APACHE II score & -1.4 & $-0.07-0.02$ & n.s. \\
Length of ventilator use & -2.0 & $-0.07-0.03$ & $*$ \\
ROAG score & 4.3 & $0.07-0.22$ & $* *$ \\
\hline
\end{tabular}

*: $\mathrm{p}<0.05,{ }^{* *}: \mathrm{p}<0.01$, n.s.: Not significant

by logistic regression analysis

Table 5. Correlation of VAP onset and ROAG categories

\begin{tabular}{llll}
\hline Items & OR & $95 \%$ CI & p value \\
\hline Lips & 2.0 & $-0.05-1.05$ & n.s. \\
Teeth/dentures & 1.4 & $-0.19-0.86$ & n.s. \\
Mucous membrane & 0.7 & $-0.35-0.73$ & n.s. \\
Gums & 0.8 & $-0.43-0.97$ & n.s. \\
Tongue & 0.8 & $-0.44-0.57$ & n.s. \\
Saliva & 3.0 & $0.12-0.78$ & $*$ \\
Condition of teeth & 1.4 & $-0.49-1.12$ & n.s. \\
Halitosis & 1.6 & $-1.23-0.24$ & n.s. \\
\hline
\end{tabular}

*: $\mathrm{p}<0.05$, n.s.: Not significant

by logistic regression analysis 


\section{Discussion}

The significance of oral care for the prevention of pulmonary infections has been increasingly recognized not only in the field of critical care medicine, but also in home healthcare and nursing homes (Watado et al., 2004; Grimoud et al., 2003). There is high possibility of lowered swallowing function and weakened immune system in patients, especially during the acute phase of systemic diseases and the perioperative period. For this reason, oral care is considered as part ofthe measures necessary to prevent VAP and postoperative infection (Feider et al., 2010; Hutchins et al., 2009). However, many perioperative factors are thought to be associated with VAP development and it is unknown to what extent oral health status and oral care are involved (Scannapieco et al., 2003; Akça et al., 2000). The present study examined the relationship between systemic factors and the evaluation items for oral health status with VAP development in perioperative patients.

Oral pathogenic bacteria have been regarded important as a major cause VAP development, as subglottic secretions run down the tracheal intubation tube; the intubation tracheal intubation tube is made from biofilm, disseminating bacteria through the peripheral airways via artificial respiration (Hutchins et al., 2009; Mori et al., 2006). Furthermore, it is surmised that pathogenic bacteria in the gastric contents are disseminated in the trachea because of gastroesophageal reflux (Scannapieco et al., 2003; ATS, IDSA, 2005). For this reason, risk factors for VAP include not only oral health status, but also a wide variety of factors such as bed angle, level of sedation, gastroesophageal reflux and prolonged oral intubation (Rello et al., 2002). Previous studies have reported a high mortality rate for emergency intubation and extended hospitalization before intubation lead to an increased risk of VAP (ATS, IDSA, 2005; Rello et al., 2002). It has also been pointed out that burns, trauma, Central Nervous System (CNS) disease and cardiopulmonary disease are possible risk factors for VAP (Cook et al.,1998). Therefore, the present study had no bias for type of disease and operative conditions of control subjects and instead examined other factors.

In the present study, a significant difference was seen between the VAP group and control group for the items of albumin before operation, length of ICU stay, length of oral intubation, length of ventilator use and ROAG score. We deduced that length of ICU stay, length of oral intubation, length of ventilator led to a worsened respiratory condition associated with VAP development, making long-term ventilator use necessary and also resulting in long-term ICU stay. We surmise that when VAP occurs, regardless of favorable or poor prognoses, length of ventilator use and length of hospitalization increases, leading to a similar trend seen in the results of the present study (Suka et al., 2007; Collard et al., 2003). On the other hand, no difference in both operative duration and APACHE II score was seen between the groups. This suggests that invasiveness of surgery in the control subjects and the severity of general condition at time of admission was the same in subjects who developed VAP as in control subjects in whom VAP did not develop. While the present study used operative duration as an indicator of level of surgical invasiveness, because use of muscle relaxants and oversedation are risk factors for VAP, a comparison with other factors related to surgical invasiveness is needed (MacIntyre, 2006). Although a difference in BMI between the VAP Group and the Control Group was not seen, the VAP Group had a higher level of albumin before operation. Undernutrition and lower serum albumin levels are generally risk factors for common pneumonia (Viasus et al., 2013). However, undernutrition that affects onset of pneumonia is defined as a serum albumin level of less than $3.0 \mathrm{~g} / \mathrm{dL}$. In the present study, the mean value of subjects was higher than the threshold. Only three subjects had serum albumin levels less than $3.0 \mathrm{~g} / \mathrm{dL}$ (one in the VAP Group and two in the Control Group), indicating that there was no problem in the nutritional status of subjects in both groups.

Factors correlated with incidence of VAP were the following: operative duration; length of ICU stay; length of ventilator use; and ROAG score. As mentioned above, length of ICU stay and length of ventilator use were thought to be due to VAP. Incidence of VAP markedly prolonged length of ICU stay and length of ventilator use and the results suggested that it also prolonged weaning from ventilators and hospital discharge. Additionally, a relationship between operative duration and incidence of VAP was noted. Prolonged operative duration affected risk of infection, postoperative mortality and postoperative pulmonary complications and was thought to be a risk factor for onset of VAP (Owen et al., 2013). ROAG score was significantly higher in the VAP Group, but because a correlation with incidence of VAP was shown, poor oral health status was suggested to be a risk factor. Furthermore, among the ROAG categories, saliva which means xerostomia was thought to increase the risk of pulmonary infections. Tube-related mucosal injury and oral ulcers were more often seen in patients for the ROAG category for evaluation of lips of only orally intubated patients more than xerochilia and angular cheilitis (Ooka et al., 2013). In cases where damage to the corners of the mouth was present, the growth of staphylococci and streptococci led to secondary bacterial infections. Staphylococci was detected in approximately $40 \%$ or patients with VAP (Woske et al., 2001). Because it was determined to be the cause of pneumonia, injury to the corners of the mouth was thought to greatly influence pneumonia. Because the intubation tube presses especially hard against the corners of the mouth, pathogenic bacteria which grew in the corners of the 
mouth were thought to possibly invade the trachea via the intubation tube. Furthermore, the category for saliva assessed the severity of xerostomia, but the results of the present study suggest that xerostomia was possibly a risk factor for VAP development. When xerostomia was present, it has been said that the risk of pneumonia increased, normal bacterial flora of the oral cavity, such as candida, also increased, as well as the changes in oral bacterial flora (Fields, 2008). It has also been reported that because orally intubated patients continue to have their mouths open, xerostomia often occurs (Ooka et al., 2013; 2012). For this reason, pathogenic bacteria, including bacteria that causes pneumonia increase because of xerostomia and are thought to be related to occurence of VAP through the intubation tube. However, no correlation was seen for VAP development and the categories for gum and tongue, which also were in contact with the intubation tube. This is thought to be because the gum score was low in both groups and the tongue score was high in both groups. These findings suggest the possibility that oral health, especially abnormalities of the lips or oral dryness seemed to be risk factors for pneumonia and oral health care is necessary in order to prevent VAP.

The present study examined the correlation between the subjective evaluation items for oral health status and VAP development and did not examine the correlation of types or amount of pathogenic bacterial flora of oral cavity with VAP development. Future research is needed to examine additional microbiological factors for risk of development of VAP and search for a relationship with other factors.

\section{Conclusion}

The results of the present study suggest that the VAP occurring in orally intubated patients is due to many factors and one of them is the oral health status. Appropriate oral hygiene management can aid the prevention of perioperative pulmonary infections.

\section{Acknowledgement}

This research was supported by JSPS KAKENHI Grant Number 23390484.

\section{Funding Information}

The authors have no support or funding to report.

\section{Author's Contributions}

Takafumi Ooka:, Research manager.

Yoshimasa Okamatsu: Study and research practitioner.

Yuriko Ando: Study and research practitioner.

Hiroshi Takano: Study and research practitioner.

Youhei Tsuru: Study and research practitioner.
Motoko Ida: Study and research practitioner.

Shouji Hironaka: Study and research practitioner.

Yasafumi Maruoka: Study and research practitioner.

Yoshiharu Mukai: Principal investigator.

\section{Ethics}

This article is original and contains unpublished material. The corresponding author confirms that all of the other authors have read and approved the manuscript and no ethical issues involved.

\section{References}

Akça, O., K. Koltka, S. Uzel, N. Cakar and K. Pembeci et al., 2000. Risk factors for early-onset, ventilator-associated-pneumonia in critical care patients: Selected multiresistant versus nonresistant bacteria. Anesthesiology, 93: 638-645. PMID: 10969295

ATS, IDSA, 2005. Guidelines for the management of adultswith hospital-acquired, ventilator-associated and healthcare-associatedpneumonia. Am. J. Respir. Crit. Care Med., 171: 388-416.

Andersson, P., I.R. Hallberg and S. Renvert, 2002. Interrater reliability of an oral assessment guide for elderly patients residing in a rehabilitation ward. Spec. Care Dentist., 22: 181-186. PMID: 12580356

Collard, H.R., S. Saint and M.A. Matthay, 2003. Prevention of ventilator-associated pneumonia: An evidence-based systematic review. Ann. Intern. Med., 138: 494-501. DOI: 10.7326/0003-4819-138-6-200303180-00015

Cook, D.J., S.D. Walter, R.J. Cook, L.E. Griffith and G.H. Guyatt et al., 1998. Incidence of and risk factors for ventilator-associated pneumonia in critically ill patients. Ann. Intern. Med., 129: 433-440. PMID: 9735080

Eilers, I., A.M. Berger and M.C. Petersen, 1988. Development, testing and application of the oral assessment guide. Oncol. Nurs. Forum, 5: 325-330. PMID: 3287344

Feider, L.L., P. Mitchell and E. Bridges, 2010. Oral care practices for orally intubated critically ill adults. Am. J. Crit. Care, 19: 175-183. PMID: 20194614

Fields, L.B., 2008. Oral care intervention to reduce incidence of ventilator-associated pneumonia in the neurologic intensive care unit. J. Neurosci. Nurs., 40: 291-298. PMID: 18856250

Grimoud, A.M., N. Marty, H. Bocquet, S. Andrieu and J.P. Lodter et al., 2003. Colonization of the oral cavity by Candida species: Risk factors in long-term geriatric care. J. Oral Sci., 45: 51-55. PMID: 12816366

Hutchins, K., G. Karras, J. Erwin and K.L. Sullivan, 2009. Ventilator-associated pneumonia and oral care: A successful quality improvement project. Am. J. Infect. Control, 37: 590-597. PMID: 19716460 
MacIntyre, N., 2006. Ventilatory Management of ALI/ARDS. Semin. Respir. Crit. Care Med., 27: 396-403. PMID: 16909373

Mori, H., H. Hirasawa, S. Oda, H. Shiga and K. Matsuda et al., 2006. Oral care reduces incidence of ventilator-associated pneumonia in ICU populations. Intensive Care Med., 32: 230-236. PMID: 16435104

Ooka, T., Y. Inoue, S. Hironaka and Y. Mukai, 2013. Effect of difference of oral health care on oral health. J. Jpn. Soc. Disability Oral Health, 34: 626-636.

Ooka, T., Y. Inoue, N. Oda, Y. Okamatsu, Y. Ando et al., 2012. Survey on the issues and the changes of oral health condition of inpatients in the intensive care unit. Dent. Med. Res., 32: 189-198.

Owen, R.M., S.D. Perez, N. Lytle, A. Patel, S.S. Davis et al., 2013. Impact of operative duration on postoperative pulmonary complications in laparoscopic versus open colectomy. Surg. Endosc., 27: 3555-3563. PMID: 23584820

Parker, C.M., J. Kutsogiannis, J. Muscedere, D. Cook and P. Dodek et al., 2008. Ventilator-associated pneumonia caused bymultidrugresistantorganismsorPseudomonasaeruginosa:

Prevalence, incidence, risk factors and outcomes. J. Crit. Care, 23: 18-26. PMID: 18359417

Rello, J., H. Lode, G. Cornaglia and R. Masterton, 2010. A European care bundle for prevention of ventilatorassociated pneumonia. Intensive Care Med., 36: 773-780. PMID: 20237759

Rello, J., D.A. Ollendorf, G. Oster, M. Vera-Llonch and L. Bellm et al., 2002. Epidemiology and outcomesofventilator-

associatedpneumoniainalargeUSdatabase. Chest, 122: 2115-2121. PMID: 12475855
Scannapieco, F.A. and M.P. Rethman, 2003. The relationship between periodontal diseases and respiratory diseases. Dent. Today, 22: 79-83. PMID: 14515580

Segers, P., R.G. Speekenbrink, D.T. Ubbink, M.L. van Ogtrop and B.A. de Mol, 2008. Prevention of nosocomial infections after cardiac surgery by decontamination of the nasopharynx and oropharynx with chlorhexidine; A prospective, randomised study. Ned. Tijdschr. Geneeskd., 152: 760-767. PMID: 18461895

Suka, M., K. Yoshida, H. Uno and J. Takezawa, 2007. Incidence and outcomes of ventilator-associated pneumonia in Japanese intensive care units: The Japanese nosocomial infection surveillance system. Infect. Control Hosp. Epidemiol., 28: 307-313. PMID: 17326021

Viasus, D., C. Garcia-Vidal, A. Simonetti, F. Manresa, J. Dorca et al., 2013. Prognostic value of serum albumin levels in hospitalized adults with community-acquired pneumonia. J. Infect., 66: 415-423. PMID: 23286966

Watado, A., S. Ebihara, T. Ebihara, T. Okazaki, H. Takahashi et al., 2004. Daily oral care and cough reflex sensitivity in elderly nursing home patients. Chest, 126: 1066-1707. PMID: 15486365

Woske, H.J., T. Röding, I. Schulz and H. Lode, 2001. Ventilator-associated pneumonia in a surgical intensive care unit: Epidemiology, etiology and comparison of three bronchoscopic methods for microbiological specimen sampling. Crit. Care, 5: 167-73. PMID: 11353934 